\title{
Assessing Customer Satisfaction And Acceptance On Perishable Goods In The "Telepresent" Environments
}

Yoon C. Cho, KDI School of Public Policy and Management, Korea

\begin{abstract}
Customer satisfaction and willingness to purchase a product in the telepresent environment varies based on how attributes of the products are easily determined. Considering the impact of the telepresent, this study explored factors that affect customer satisfaction and willingness to adopt perishable goods. This study also considered customer satisfaction and willingness to purchase products based on their previous experiences with online or other interactive home shopping wherein they encountered limitations in delivery of certain features or product attributes. The purpose of this study is to examine factors that affect customer satisfaction and willingness to purchase perishable goods in the online environment and how experiences with sensory goods (besides perishable goods) from online and other interactive home shopping channels affect satisfaction and willingness to purchase perishable goods. Surveys were conducted and statistical analyses, such as factor, regression, ANOVA, and ANCOVA, were applied to investigate the findings. Further, this study provides managerial and theoretical implications and offers suggestions for e-businesses.
\end{abstract}

Keywords: E-Commerce, Customer Attitude, Telepresence, Product Category, Satisfaction, Willingness to Purchase.

\section{INTRODUCTION}

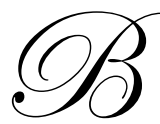

y virtualization, parties involved in an exchange use computer-mediated communication (CMC) systems as a means of establishing interpersonal, inter-organizational, and intra-organizational contact. "Telepresence" has gained attention with the virtualized process, such as e-commerce, ebusiness, and the emergent I-Way economy that enables individuals, organizations, and automated systems to coordinate all aspects of the consumer buying process (Cho 2003). Businesses that encounter "telepresence" utilize applications to overcome limitations, such as delivering certain aspects of product attributes. Due to such limitations, e-businesses focus on increasing "interactivity" via machines in order to minimize gaps in the physical appearance of products attribute, particularly with sensory products. The gaps occur during the decision-making process due to computer-mediated communication.

Consumer buying decisions in the "telepresent" environment depend on the product category and on how easily the customer can determine product quality remotely (Figuiredo 2000). Researchers noted that product attributes are an important key for consumers on the Web to judge product quality and to make a purchase decision (Degeratu et al. 2001; Figueiredo 2000; Kiely 1996). In an online environment, consumers must consider the risk and uncertainty of product classifications due to the inherent limitations of e-businesses (i.e., product quality delivered via Computer-Mediated Communication (CMC) system; Cho 2009). Figuiredo (2000)'s dot com retail continuum classified product categories on the Web by considering whether customers could easily evaluate product attributes. As proposed in previous research (Cho 2010), products such as perishable grocery goods, clothes, and shoes, with limitations in delivering sensory input through the web had less appeal to online customers than did nonsensory products, such as books and computers. This held true for other reasons as well, such as margins and other distribution-related issues. 
While virtualization and telepresence have the peculiar characteristics of online business, other traditional retail formats, such as catalogues and interactive home shopping, also face similar limitations because product quality cannot be determined easily due to absence of physical presence (i.e., absence of perceived senses via touch/see/smell and of a certain degree of human intervention). According to a previous study by Alba et al. (1997), Interactive Home Shopping (IHS), as a confluence of technological, economic, and cultural forces, made possible a new and revolutionary distribution channel, suggesting what it offers consumers could motivate them to alter their present shopping behavior. The interactive component or "Interactivity," in IHS, implies a continuous construct capturing the quality of two-way communication between two parties (Alba et al. 1997) elaborated in the context of electronic media (Hoffman and Novak 1996). As a previous study (Alba et al. 1997) addressed, such channels affected customers' attitudes and purchase decision in the telepresent environment because they enabled highly reliable inferences about consumption benefits after a single purchase and use. Major limitations in interactive home shopping, as well in "telepresence", include how to reveal the sensual because customers cannot see/touch/smell the product directly. A study by Cho (2003) raised the managerial question of predicting and planning for success rather than failure, taking telepresence to the areas where it could build a competitive advantage and user value, and thus prove to be a sound business effort. This study posits that issues of telepresence, such as customer choice behavior, decision-making, and purchase patterns, have affected businesses, including e-business and other direct channels, such as interactive home shopping (IHS).

Based on the considerations above, this study explores customer attitudes and satisfaction toward sensory products in the online environment. Among sensory goods, this study examined customer satisfaction and conative feelings toward perishable goods, and the impact of prior experiences of purchasing behavior in the telepresent environment, including online and other interactive home shopping. Therefore, the purpose of this study is to explore the factors affecting attitudes, willingness to purchase, and satisfaction with perishable goods for online customers; how such attitudes are formed based on prior experiences with purchasing other sensory goods online; and how such attributes are formed based on prior experiences of purchasing sensory goods from interactive home shopping channels besides online.

\section{HYPOTHESES DEVELOPMENT}

Researchers paid attention to customers' attitudes in the telepresent environment because customers display different purchasing behavior due to the availability of delivering product attributes. The role of interactivity is imperative in the environment because it plays a pivotal role in communicating with consumers. A previous study (Hoffman, Novak, and Chatterjee 1995) stated that interactivity contributed to the rapid diffusion of the Web as a commercial medium for many years. Authors stressed that the web relied heavily on "customer or user interactions" in a Hyper Media Computer Mediated Environments (HCMEs: Hoffman, Novak, and Chatterjee 1995) by significantly applying characteristics of interactivity. As shown in Figure 1, CMC plays a role as an intermediary if customers have virtual experience via telepresence in the market-space (Cho 2008). Compared to physical or online market with limited interaction ( $\&$ b), online market with unlimited interactivity signals communication between customers and/or between customers and machines.

Theories, such as telepresence theory (Steuer 1992) and interactivity theory (Rafaeli 1988), provide a conceptual basis to support the role of interactivity in the telepresent environment (see also Song and Zinkhan 2008). Steuer (1992) proposes the term "telepresence" to distinguish the mediated aspect of the experience of presence in a virtual environment. According to Steuer (1992), telepresence refers to "the mediated perception of an environment" and interactivity defines as "the extent to which users can participate in modifying the form and content of a mediated environment in real time." The role of "interactivity" in the environment involves different settings and the environment needs to deliver advanced services compared to traditional economic activities, which are undergoing a profound transformation. While interactivity theory addressed communication quality influencing users' perceptions and effectiveness (Song and Zinkhan 2008), how to maximize the customer satisfaction and increase acceptance still remain a consideration in the telepresent environment. Previous studies noted that the level of interactivity depended on the characteristics of the media. The essential underlying principle in both theoretic traditions is that a good match between the characteristics of a medium (such as high social presence or media richness) and one's communication activities (such as socio-emotional activities touching an online salesperson) can lead to "better" (more effective, satisfying, etc.) performance (Hiltz \& Turoff 1978; Rice 1993; Rice \& Love 1987; Daft \& Lengel 1986). 


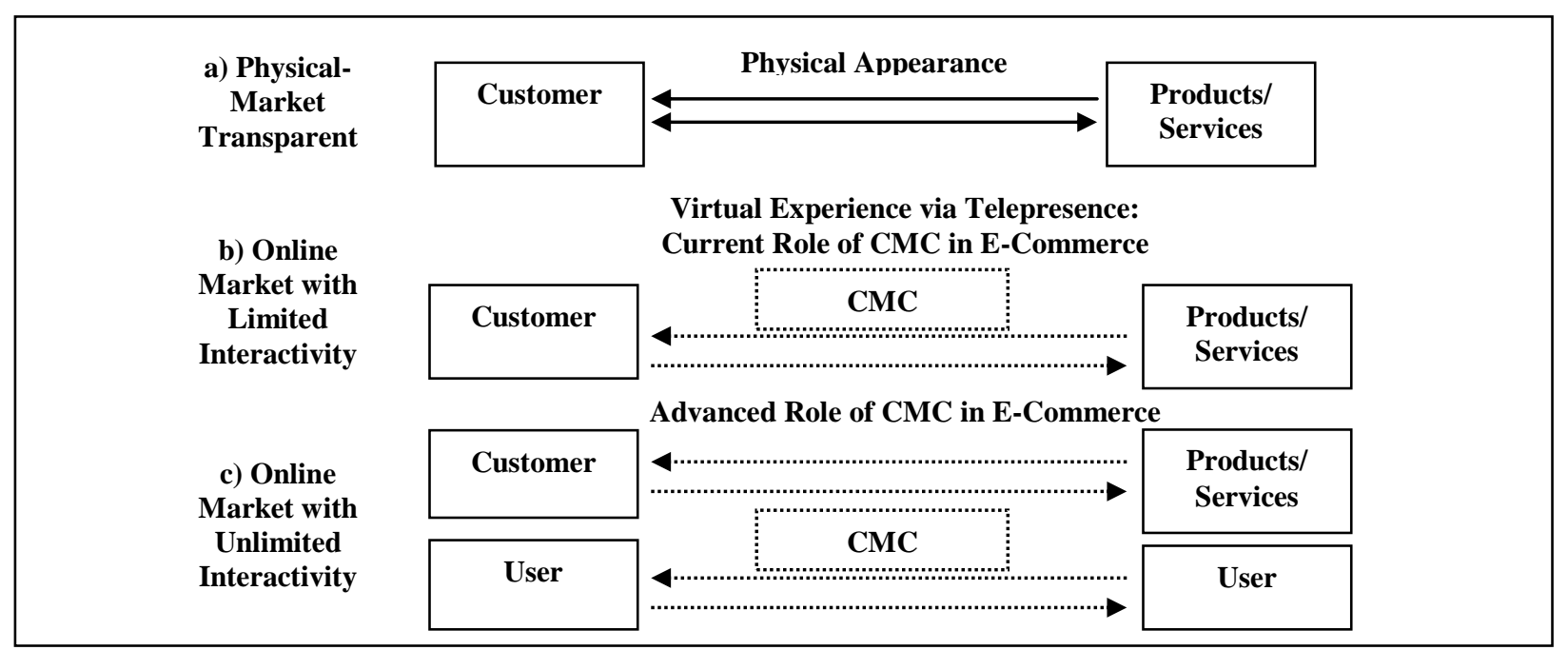

Figure 1: The Evolving Role of Interactivity in Computer-Mediated Communication (Modified from Cho 2008)

This study measures the impact of proposed factors, such as convenience, perceived convenience, information, product quality, price, and reliability, which might affect customers' willingness to purchase and their potential satisfaction (Figure 2). Some research addressed different effects based on customer groups due to differing experiences in purchasing perishable goods online. A study by Alba and Hutchinson (1987) proposed familiarity and expertise (cf. Jacoby et al. 1986) as important dimensions of consumer knowledge related variables, which have become an independent area of research and theory. Hansen (2005) proposed grouping online customers based on innovative characteristics, such as risks with purchasing perishable goods. By segmenting three groups of customers based on their online usage and purchasing experiences, Hansen (2005) analyzed discrimination with innovative characteristics (e.g., social norms, complexity, compatibility, relative advantage, and Internet grocery risk).

This study investigated customers' attitudes toward grocery related perishable goods in particular. A study by Forsythe and Shi (2003) noted that customers' reluctance to adopt the internet as an online grocery shopping channel related to perceived internet (grocery) risk and their perception of potential losses or harm. In fact, due to the issue of telepresence, which deals with the limitations of delivering input to the senses and managing perishable grocery goods online, online grocery businesses received less attention and experienced difficulties (Cho 2010). Hansen (2005) remarked that internet grocery shopping has faced serious difficulties in spreading to consumers (Ring \& Tigert 2001; Geuens et al. 2003) like many other innovations (Frambach et al. 1998). This study also examined how previous experiences of purchasing sensory goods online affected customers' willingness to purchase perishable goods or to express satisfaction with them. This study also investigated the impact of previous purchases of sensory goods from channels without presence (e.g., catalogues, interactive TV home shopping) besides online and whether those experiences affected customers' willingness to purchase perishable goods or their satisfaction with them.

The impact of previous experiences on purchasing other sensory goods, or attitude for the purposes of this study is a learned association in memory between an object and a positive or negative evaluation of that object. Attitude strength is equivalent to the strength of this association (Fazio 1990). The MODE (Motivation and Opportunity act as Determinants of Spontaneous versus deliberative attitude-to-behavior processes) model by Fazio (1995) suggested that attitude strength - in the form of its accessibility in memory - played a pivotal role in the link between attitudes and behavior. Particularly in the telepresent environment, a customer' propensity to adopt (e.g., willingness to purchase) a product is explained by the diffusion of innovation theory. Innovation diffusion typically operationalizes adoption behavior as an individual's adoption time - that is, the elapsed time between the market introduction of an innovative product and the individual's first acquisition of it [Lam, Chiang, and Parasuraman 2008 (Danaher, Hardie, and Putsis 2001; Rogers 2003)]. 


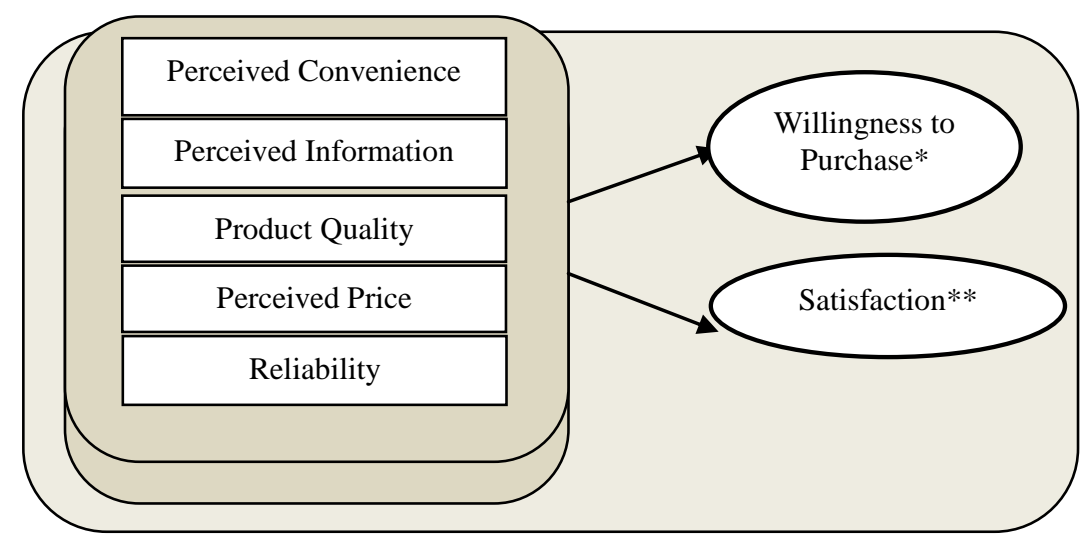

*Impacts of factors to willingness to purchase applied to the case of non-purchase experiences of perishable goods online **Impacts of factors to satisfaction applied to the case of purchase experiences of perishable goods online.

Figure 2: Factors that Affect Willingness to Purchase and Satisfaction on Perishable Goods in the Telepresent Environment

Customer satisfaction theories supported this study. Contrast theory (Engel \& Blackwell 1982; Cardozo 1965) explained the level of (dis)comfort between expectations and actual outcome, while dissonance theory (Festinger 1957) stressed that inconsistency induced psychological discomfort associated with risky consumption, including innovations of all varieties with potentially dangerous consequences (Oliver 1997). This study posits that customers' expectation based on prior purchasing experiences of similar sensory goods online and through other channels that "without presence" will affect their satisfaction and willingness to purchase other products. Customers' attitudes in a new media, such as online, could be also explained by discrepancy theory found in models of satisfaction with media communications, where the performance judgment and its comparative referent are referred to as gratifications received and gratifications sought [Oliver 1997 (Dobos 1992; Palmgreen \& Rayburn 1985; Wenner 1986)]. Because the purpose of this study includes how customers' previous experiences with sensory goods affect their willingness to purchase groceries online, the Theory of Reasoned Action (TRA) also supports the proposal that individuals' performance of a given behavior is primarily determined by their intention to perform that behavior (Ajzen \& Fishbein, 1980). The Technology Acceptance Model (Davis 1989), which has been widely used in the research on online user behavior to describe user/customer attitudes and behavior in the e-commerce environment, also helps explain this study because customers' previous experiences of sensory goods are significantly affected by user acceptance (Cho 2010). The Technology Acceptance Model (Davis 1989) supported this study describing how people form evaluative beliefs or perceptions about the ease of use and usefulness of a website, and integrate such beliefs to form their usage intention of the technology.

\section{Perceived Convenience}

"Convenience" is a significant factor that affects customers' satisfaction and willingness to purchase products in an electronic environment. E-businesses focus on convenience by addressing high levels of accessibility and interactivity in the telepresent environment. While there are limitations in the online environment compared to the offline environment, such as lack of assistance by a salesperson and sensual impressions, online customers' acceptance level has gradually increased because of the perceived benefits, such as convenience. As customers' propensity to embrace and use new technologies (Lam, Chiang, and Parasuraman 2008) ${ }^{1}$ increase, customers' willingness to purchase perishable goods also increases. Enhanced services that minimize customer complaints play a role to in enhancing willingness to purchase even perishable goods online. Today's advanced technology allows enhanced service quality that affects customer's adoption rates. A study by Bitner et al. (2000) discussed the role of technology in implementing effective service recoveries and encouraging customer feedback or complaints (see also

\footnotetext{
${ }^{1}$ Authors assigned the term, the Technology-Readiness (TR) that consumers' propensity to embrace and use new technologies for accomplishing goals in home life and at work.
} 
Brown 1997). As also stated by researchers (Figueiredo 2000; Cho et al. 2003), online business excel at customer service in order to enhance interactivity, such as real time customer support. A previous study by Cho et al. (2003) addressed the importance of online businesses, especially those selling "look-and-feel goods" and "look-and-feel" with variable quality products, offering superior customer service (Cho et al. 2003), in order to minimize uncertainty about their products.

This study hypothesized that the ways in which customers perceive the convenience of purchasing perishable goods online affects their satisfaction and willingness to purchase. This study also hypothesized that the perceived convenience is contingent on previous experiences of purchasing sensory goods online and from other retailers with limitations of presence.

H1a-2a: As the degree of customers' perceived convenience in purchasing perishable goods online becomes higher, their overall satisfaction (or willingness to purchase) is also higher when customers have (or do not have) experiences of purchasing perishable goods online.

H1b-2b: The effects of customers' perceived convenience in purchasing perishable goods on their overall satisfaction (or willingness to purchase) will be higher if customers have positive experiences purchasing sensory goods online besides perishable goods.

H1c-2c: The effects of customers' perceived convenience in purchasing perishable goods on their overall satisfaction (or willingness to purchase) will be higher if customers have positive experiences purchasing sensory goods from other direct marketing marketplaces besides those online.

\section{Perceived Information}

How customers obtain and perceive information reveals as an important cue for decision-making. How customers obtain information to support their attribution paradigms affects satisfaction and intention and advances the decision-making process in both online and offline environments. Degeratu, Rangaswamy, and Wu (2001) pointed out that information availability affects consumers' decision-making, particularly in online environments. Customers' attitudes toward non-sensory products such as books and computers, where attributes are delivered enough via Web by information was more positive than those toward sensory products, such as clothes and shoes, in the beginning of the Internet presence era due to the degree with which attributes of the products were delivered. How much the Web minimizes the gap of delivering attributes (particularly sensory attributes) of the products due to absence of presence is as an important cue for the success of e-businesses. Dick et al. (1990) noted that consumers focus on relevant available attributes and are diagnostic when they search for information in the online context. Current websites provide a certain degree of information and most online users have the ability to access that information (Cho 2004). By applying advanced technology, businesses that cannot directly deliver sensual content put more effort into delivering information in order to reduce uncertainty. A study by Cho and $\mathrm{Ha}$ (2003) reported that the quality of content provided by websites reduced users' search efforts and created their intention to use.

This study hypothesized that the way in which customers perceive information on purchasing perishable goods online affects satisfaction and their willingness to purchase based on their previous purchasing experiences of buying perishable goods online. This study also hypothesized that the perceived information on the satisfaction (or willingness to purchase) was contingent on their previous experiences of purchasing sensory goods online and through other retailers with limited presence.

H3a-4a: As the degree of customers' perception of information when purchasing perishable goods online is higher, their overall satisfaction (willingness to purchase) is also higher if customers have experiences of purchasing perishable goods online.

H3b-4b: The effects of customers' perception of the convenience of purchasing perishable goods on their overall satisfaction (willingness to purchase) will be higher if customers have positive experiences of purchasing sensory goods online besides perishable goods. 
H3c-4c: The effects of customers' perception of the convenience of purchasing perishable goods on their overall satisfaction (willingness to purchase) will be higher if customers have positive experiences of purchasing sensory goods from other direct marketing marketplaces besides those online.

\section{Product Quality}

How customers perceive the quality of the product in the telepresent environment an important issue for ebusinesses because various descriptions of the attributes of the product are unavailable via the Web. E-businesses have applied advanced technologies to minimize customers' reluctant to purchase products with sensory attributes. According to Figueiredo (2000), customers need to see and touch products, such as produce and art, despite recognizing the brand and knowing the product. Therefore, customers are not likely to purchase sensory products with variable quality online because their satisfaction after the purchase might not reach their prior expectations. Thus, in an effort to fulfill customer expectations for those products, e-businesses sell sensory products by providing customized technologies, such as pictures of the products, enlargements of the products, size charts, etc. (Cho 2004). Figueiredo (2000) suggested that dot-coms dealing with "look-and-feel goods" and "look-and-feel" with variable quality should excel in customer interfacing using advanced technology.

This study hypothesized that the ways in which customers perceive the quality of purchasing perishable goods online affect satisfaction and willingness to purchase based on their previous purchasing experiences of perishable goods online. This study also hypothesized that the perceived product quality on the satisfaction (or willingness to purchase) is contingent on previous experiences of purchasing sensory goods online and from other retailers with limited presence.

H5a-6a: As the degree of customers' perception of product quality when purchasing perishable goods online is higher, their overall satisfaction (willingness to purchase) is also higher if they have experiences of purchasing perishable goods online.

H5b-6b: The effects of customers' perception of product quality in purchasing perishable goods on their overall satisfaction (willingness to purchase) will be higher if they have positive experiences of purchasing sensory goods online besides perishable goods.

H5c-6c: The effects of customers' perception of product quality in purchasing perishable goods on their overall satisfaction (willingness to purchase) will be higher if they have positive experiences of purchasing sensory goods from other direct marketing marketplaces besides those online.

\section{Perceived Price}

Price is an important factor in the online environment and has become unquestionably one of the most important marketplace cues (Lichtenstein, Ridgway, and Netermeyer 1993). Customers' price sensitivity significantly affects their decision-making behavior in the online environment as. They can engage in intensive price comparisons through sites that provide such services. Customer selection of retail stores rely on price and forms of promotional strategy offered including price discounts. Online consumers' expectations for lower prices could be even higher than in the offline environment because e-businesses often provide lower prices and manage efficient distribution systems. When online stores maintain an efficient distribution system, they are better able to reduce costs; however they do not always offer lower prices than do physical stores (Cho 2004). Based on this consideration, this study also suggests that e-businesses should employ better pricing strategies to meet consumers' expectations, particularly when customers take risks and have uncertainty about perishable goods. Figueiredo (2000) suggested different pricing strategies for different product categories. In particular, creative pricing strategies should apply to "look-and-feel goods," specifically for time- preference based pricing (Figueiredo 2000).

This study hypothesized that the ways in which customers perceive the price of perishable goods online affect satisfaction and willingness to purchase based on their previous purchasing experiences. This study also hypothesized that the perceived price on satisfaction (or willingness to purchase) is contingent on previous experiences of purchasing sensory goods online and through other retailers with limited presence. 
H7a-8a: As the degree of customers' perception of price in purchasing perishable goods online is higher, overall satisfaction (willingness to purchase) is also higher if they have experiences in purchasing perishable goods online.

H7b-8b: The effects of customers' perception of price in purchasing perishable goods on the overall satisfaction (willingness to purchase) will be higher if they have positive experiences of purchasing sensory goods online besides perishable goods.

H7c-8c: The effects of customers' perception of price in purchasing perishable goods on the overall satisfaction (willingness to purchase) will be higher if they have positive experiences of purchasing sensory goods from other direct marketing marketplaces besides those online.

\section{Reliability}

Even with the limitation of "without-presence," some e-businesses successfully approach customers and deliver the sensory attributes of the products by focusing on their reliability. Customers' attitudes toward retailers that do not deliver sensory attributes of the products form positively or negatively based on the reliability of the brand name, beliefs based on the previous experiences, and trust of the business for any reason (e.g., excellent service). As customers need to assume higher levels of perceived risk and uncertainty in purchasing perishable goods online, e-businesses need to maximize customer trust by delivering information via words and pictures. Even with perceived risk and uncertainty, online grocery markets have gradually increased due to various reasons, such as changes in customer adoption of innovations, development of the e-business (e.g., how the business delivers information to minimize risks), or changes in societal structure (e.g., increased rates of single and/or reduced family size) (Cho 2010).

This study hypothesized that how customers perceive the reliability of purchasing perishable goods online affects satisfaction and willingness to purchase based on their previous purchasing experiences with perishable goods online. This study also hypothesized that the perceived reliability on the satisfaction (or willingness to purchase) is contingent on previous experiences of purchasing sensory goods online and from other retailers with limited presence.

H9a-10a: As the degree of customers' perception of reliability in purchasing perishable goods online is higher, overall satisfaction (willingness to purchase) is also higher if they have experiences of purchasing perishable goods online.

H9b-10b: The effects of customers' perception of reliability in purchasing perishable goods on the overall satisfaction (willingness to purchase) will be higher if they have positive experiences of purchasing sensory goods online besides perishable goods.

H9c-10c: The effects of customers' perception of reliability in purchasing perishable goods on the overall satisfaction (willingness to purchase) will be higher if they have positive experiences of purchasing sensory goods from other direct marketing marketplaces besides those online.

\section{METHODOLOGY}

\section{Data Collection}

This study measures factors that affect customers' satisfaction and willingness to purchase perishable goods in the telepresent environment. This study also measure effects based on customers' previous experiences of purchasing sensory goods in the online environment and other similar environments that have limitation of physical presence. Survey has been designed to targeted customers who have experiences of non-purchasing or purchasing perishable grocery goods online and with the following questions asking experiences of purchasing sensory goods from online and other direct channels besides online. This study conducted a survey with the assistance of wellknown research firm that have profound experiences of online research. Participants were selected from panels that 
have online purchasing experiences and also sensory goods purchasing experiences from similar channels that have "without presence" characteristic. Sampling has been conducted with structure by considering factors such as gender, age, education, income, and geographical locations. A total of six hundred twenty respondents completed the survey (i.e., three hundred twenty one responds were collected from customers who had purchasing experiences of perishable grocery goods online and three hundred responds were collected from those who don't have purchasing experiences of perishable grocery goods online, but have experiences of purchasing experiences of sensory goods from online and other channels that have characteristics of without-presence). Response rate was about $45.1 \%$.

\section{Operational Measures}

Multi-item scales were used to measure each of the seven constructs that served as the basis for the questionnaire items. The item scales were taken from previous studies (e.g., Bearden and Teel 1983; Ajzen and Fishbein 1980; Oliver 1997) and modified to serve the objectives of the present study. Quantitative methods, including factor analysis, regression, ANOVA (Analysis of Variance), and ANCOVA were applied to measure satisfaction and willingness to purchase perishable grocery goods. Likert scales, semantic differential scales, and open-ended questions were used to measure the items. For Likert scale questions, a seven-point scale was used with labels such as "Strongly Disagree" and "Strongly Agree" was used.

\section{RESULTS}

\section{Respondent Demographics}

Of the six hundred twenty respondents, $48.6 \%$ were female and $51.4 \%$ were male. From a group of respondents who have perishable grocery good experiences, $54.1 \%$ were female and $45.9 \%$ were male. From another group of respondents who does not have perishable grocery good experiences, $41.0 \%$ were female and $59.0 \%$ were male. About $23.1 \%$ and $31.5 \%$ were between the ages of 20-29 from the respondents of non-purchasing and purchasing perishable grocery goods online; $27.0 \%$ and $28.5 \%$ were between the ages $30-39$ from the respondents of none-purchasing and purchasing perishable grocery goods online; $31.6 \%$ and $26.2 \%$ were ages $40-49$ from the respondents of non-purchasing and purchasing perishable grocery goods online); and $18.3 \%$ and $13.7 \%$ were ages of 50 or older from the respondents of non-purchasing and purchasing perishable grocery goods online. Approximately $22.7 \%$ and $32.8 \%$ reported that their highest educational level was high school graduate from the respondents of non-purchasing and purchasing perishable grocery goods online, $14.2 \%$ and $17.6 \%$ had an associate degree from the respondents of non-purchasing and purchasing perishable grocery goods online, $54.2 \%$ and $42.3 \%$ had an undergraduate degree from the respondents of non-purchasing and purchasing perishable grocery goods online, and $8.9 \%$ and $7.3 \%$ had an graduate degree from the respondents of non-purchasing and purchasing perishable grocery goods online). Respondents' status related to work also have been varied including students, housewives, business person,

In order to check construct reliability, this study measured Cronbach's alpha for multi-item scales to measure each of the constructs that served as the basis for the questionnaire items. This study found that Cronbach's alpha for convenience construct shows $0.852 \%$ (in case of purchase) and $0.886 \%$ (in case of non-purchase), perceived information shows $0.785 \%$ (in case of purchase) and $0.894 \%$ (in case of non-purchase), perceived quality construct shows $0.705 \%$ (in case of purchase) and $0.805 \%$ (in case of non-purchase), perceived price shows $0.809 \%$ (in case of purchase) and $0.780 \%$ (in case of non-purchase), and reliability construct shows $0.880 \%$ (in case of purchase) and $0.906 \%$ (in case of non-purchase).

\section{Hypotheses Testing}

The first step in this analysis was intended to validate the factors, such as convenience, perceived information, perceived quality, perceived price, and reliability. This study ran a confirmatory factor analysis to identify those factors (see Table 1). Separate factor analyses were applied for the case of non-purchase and purchase perishable goods online. The study considered non-purchase experiences of non-purchasing perishable goods online but with experiences of purchasing sensory goods from online and other channels with the limitation of presence. 
Using principal components analyses as the extraction method and Varimax rotation methods with Kaiser Normalization, the most relevant data emerged. These analyses showed distinct reduced factors, with Eigen values over 1.00 both in the case of non-purchase and purchase. This study analyzed simple linear regression analyses, the analyses of variance (ANOVA), and the analysis of covariance (ANCOVA). Factor scores were used for regression analyses. This study used regression analyses for the impacts of variables to the predictors.

Table 1: Component Matrix

\begin{tabular}{|l|l|l|r|}
\hline \multicolumn{1}{|c|}{ Factors } & Components for Purchasing & \multicolumn{1}{|c|}{ Factors } & Components for Non-Purchasing \\
\hline Convenience II & .804 & Convenience III & .822 \\
Convenience IV & .716 & Convenience I & .737 \\
Convenience III & .678 & Convenience II & .691 \\
Convenience I & .616 & Convenience I & .631 \\
& & & .757 \\
Information I & .756 & Information II & .744 \\
Information V & .745 & Information VI & .693 \\
Information III & .679 & Information I & .597 \\
Information IV & .668 & Information V & .748 \\
Quality I & .745 & Quality II & .711 \\
Quality III & .741 & Quality I & .691 \\
Quality V & .629 & Quality IV & .780 \\
Price IV & .730 & Price V & .711 \\
Price V & .723 & Price II & \\
Price III & .619 & & .825 \\
Reliability II & .805 & Reliability III & .785 \\
Reliability V & .753 & Reliability II & .672 \\
Reliability III & .712 & Reliability VI & \\
Reliability IV & .701 & & \\
\hline
\end{tabular}

This study analyzed simple linear regression analyses and the analyses of variance (ANOVA). Factor scores were used for regression analyses. This study used regression analyses for the impacts of variables to the dependent variables. Table 2 presents the results of the regression analyses for the effects of variable to the dependent variables based on the Figure 2.

The results in Table 2 show the results of hypotheses 1a - 10a (hypotheses "a" of odd numbers for the case of purchase (effects to the satisfaction) and even numbers for the case of purchase (effects to the willingness to purchase)). The results of the analysis of variance in the case of purchase found the models significant at the .01 level with $F=29.029$ (two-tailed, $r$-square $=.433$ ). The results of the analysis of variance in the case of nonpurchase found the models significant at the .01 level with $F=13.014$ (two-tailed, $r$-square $=.295$ ). Thus, hypotheses H1a - 10a were accepted.

Table 2: Summary of the Effects of Variables for Both Cases of Non-Purchase and Purchase

\begin{tabular}{|l|c|c|}
\hline \multirow{2}{*}{\multicolumn{1}{|c|}{ Variables }} & \multicolumn{2}{c|}{ Standardized Coefficient $(\boldsymbol{t}$-value-Sig) } \\
\cline { 2 - 3 } & Satisfaction & Willingness to Purchase \\
\hline Perceived Convenience (h1a-2a) & $.354\left(7.630^{* * *)}\right.$ & $.190\left(3.287^{* * *}\right)$ \\
\hline Perceived Information (h3a-4a) & $.173\left(3.730^{* * *)}\right.$ & $.224\left(3.881^{* * *}\right)$ \\
\hline Product Quality (h5a-6a) & $.180\left(3.878^{* * *}\right)$ & $.191\left(3.301^{* * *}\right)$ \\
\hline Perceived Price (h7a-8a) & $.286\left(6.140^{* * *)}\right.$ & $.225\left(3.892^{* * *}\right)$ \\
\hline Reliability (h9a-10a) & $.315\left(6.764^{* * *}\right)$ & $.181\left(3.101^{* * *}\right)$ \\
\hline
\end{tabular}

*** Significant at 0.01 level (2-tailed); ** Significant at 0.05 level (2-tailed); * Significant at 0.1 level (2-tailed) 
ANCOVA (Analysis of Covariance) was applied in this study in order to examine the effect of variables on satisfaction (or willingness to purchase) based on positive or negative experiences of sensory good purchasing experiences in the online environment. The results in Table 3 show the results of hypotheses $1 \mathrm{~b}-10 \mathrm{~b}$ (hypotheses $1 \mathrm{~b}, 3 \mathrm{~b}, 5 \mathrm{~b}, 7 \mathrm{~b}$, and $9 \mathrm{~b}$ for the case of purchase and $2 \mathrm{~b}, 4 \mathrm{~b}, 6 \mathrm{~b}, 8 \mathrm{~b}$, and $10 \mathrm{~b}$ for the case of non-purchase). The results of ANCOVA showed that the impacts based on positive/negative experiences of purchasing sensory goods in the online environment were significant except the impact of quality on willingness to purchase in the case of nonpurchasing experiences of sensory goods online.

Table 3: Summary of the Effects based on Positive/Negative Experiences of Sensory goods from Online

\begin{tabular}{|l|c|c|}
\hline Effects of Customers' Perception on Convenience of Purchasing Perishable & \multicolumn{2}{|c|}{ F-value (Sig) } \\
\cline { 2 - 3 } $\begin{array}{l}\text { Goods on the Overall Satisfaction (Willingness to Purchase) based on } \\
\text { Previous Experiences of Purchasing Sensory Goods from Online }\end{array}$ & Purchase & Non-Purchase \\
\hline Predictive Convenience on Satisfaction/Willingness to Purchase (h1b-2b) & $11.223\left(0.001^{* * *}\right)$ & $6.853\left(0.000^{* *}\right)$ \\
\hline Predictive Information on Satisfaction/Willingness to Purchase (h3b-4b) & $9.212\left(0.003^{* * *}\right)$ & $67.511\left(0.000^{* * *}\right)$ \\
\hline Predictive Quality on Satisfaction/Willingness to Purchase (h5b-6b) & $31.359\left(0.000^{* *}\right)$ & $.563(0.454)$ \\
\hline Predictive Price on Satisfaction/Willingness to Purchase (h7b-8b) & $5.863\left(0.016^{* *}\right)$ & $10.989\left(0.001^{* * *}\right)$ \\
\hline Reliability on Satisfaction/Willingness to Purchase (h9b-10b) & $12.980\left(0.000^{* * *}\right)$ & $15.145\left(0.000^{* * *}\right)$ \\
\hline
\end{tabular}

*** Significant at 0.01 level (2-tailed); ** Significant at 0.05 level (2-tailed); * Significant at 0.1 level (2-tailed)

Another ANCOVA (Analysis of Covariance) was also applied in this study in order to examine the effect of variables on satisfaction (or willingness to purchase) based on positive or negative experiences of sensory good purchasing experiences in the telepresent environments of other direct channels besides online. The results in Table 4 show the results of hypotheses $1 \mathrm{c}-10 \mathrm{c}$ (hypotheses $1 \mathrm{c}, 3 \mathrm{c}, 5 \mathrm{c}, 7 \mathrm{c}$, and $9 \mathrm{c}$ for the case of non-purchase and $2 \mathrm{c}, 4 \mathrm{c}$, $6 \mathrm{c}, 8 \mathrm{c}$, and 10c for the case of purchase). The results of ANCOVA showed that the impacts based on positive/negative experiences of purchasing sensory goods in the environments of direct channels besides online were significant. Therefore, hypotheses H1c - 10c were accepted.

Table 4: Summary of the Effects based on Positive/Negative Experiences of Sensory goods from Other Direct Channels besides Online

\begin{tabular}{|l|c|c|}
\hline Effects of Customers' Perception on Convenience of Purchasing & \multicolumn{2}{|c|}{ F-value (Sig) } \\
\cline { 2 - 3 } $\begin{array}{l}\text { Perishable Goods on the Overall Satisfaction (Willingness to Purchase) } \\
\text { based on Previous Experiences of Purchasing Sensory Goods from Other } \\
\text { Channels that have without-Presence Environment besides Online }\end{array}$ & \multirow{2}{*}{ Purchase } & Non-Purchase \\
\hline Predictive Convenience on Satisfaction/Willingness to Purchase (h1c-2c) & $10.302\left(0.001^{* * *)}\right.$ & $10.891\left(0.001^{* *}\right)$ \\
\hline Predictive Information on Satisfaction/Willingness to Purchase (h3c-4c) & $5.149\left(0.024^{* *}\right)$ & $15.145\left(0.000^{* * *}\right)$ \\
\hline Predictive Quality on Satisfaction/Willingness to Purchase (h5c-6c) & $33.003\left(0.000^{* * *)}\right.$ & $2.813\left(0.096^{* *}\right)$ \\
\hline Predictive Price on Satisfaction/Willingness to Purchase (h7c-8c) & $14.216\left(0.000^{* *}\right)$ & $13.365\left(0.000^{* * *}\right)$ \\
\hline Reliability on Satisfaction/Willingness to Purchase (h9c-10c) & $13.071\left(0.000^{* *}\right)$ & $5.097\left(0.025^{* *}\right)$ \\
\hline
\end{tabular}

*** Significant at 0.01 level (2-tailed); ** Significant at 0.05 level (2-tailed)

\section{DISCUSSION AND CONCLUSION}

"Virtualization" and "telepresent" have been a significant issue for business that could not deliver senses directly and have played a pivotal issue to measure the success of business depends on how to minimize gap to deliver senses cognitively and emotionally remotely. By understanding the importance of the concept, consumer behavior with "telepresent environment," the purpose of this paper is to investigate factors that affect customer satisfaction and willingness to purchase perishable goods in the online environment. This study posits that customer attitudes toward telepresent environment have greatly affected by characteristics that adopt the new environment and also prior experiences of purchasing sensory goods in online and also other channels that have similar characteristics. By classifying two customer groups, those with purchasing or non-purchasing experiences of perishable goods online, this study measures the effects based on prior experiences. In addition, this study also measures customers' attitude and adoption of perishable goods in the telepresent environment based on prior 
experiences of purchasing sensory goods besides perishable goods online and other environment that has similar limitations i.e., without presence.

This study applied and developed concepts from previously proposed theories and models, such as innovation theory and model of satisfaction. Furthermore, this study provides implications and offers suggestions for e-businesses development and customer attitude. By considering the limitation of e-businesses and other direct channel that could not deliver senses directly, this study provide implications to e-businesses to develop better strategies in order to meet customer expectation and minimize customer dissatisfaction. This study suggests that there are opportunities for the online grocery business. By considering the late acceptance and usage of the online grocery businesses, various e-marketing applications could be utilized to grasp customer attention and acceptance. This study addressed how e-businesses need to develop strategies by combining marketing strategies and also by applying appropriate technologies. Advanced applications delivering senses via tepresence to overcome the inherent limitation of the online grocery business should be applied to maximize customer satisfaction. The author believes that more applications and usages will lead to higher customer satisfaction and loyalty toward e-commerce customer relationship management (CRM).

The study has some limitations. Although this study used multivariate statistics, such as factor and regression analysis, ANOVA, and ANOCOVA, the study did not measure the cause and effect relationship using a program, such as LISREL. The researchers will consider this issue in future research. For future studies, researchers will also investigate causes that affect different impacts toward online grocery business and also crosscultures/countries. For further studies, a larger number of subjects will be surveyed.

\section{AUTHOR INFORMATION}

Dr. Yoon C. Cho is Associate Professor at the KDI SCHOL OF PUBLIC POLICY AND MANAGEMENT, global school, located in Seoul. Previously, she was Associate Professor at Hawaii Pacific University. She received Ph.D. from Rutgers, The State University of New Jersey and MBA from Cornell University. She published research papers in the various academic journals such as Advances in Consumer Research (ACR), Journal of Consumer Satisfaction, Dissatisfaction, and Complaining Behavior (JCS/DCB), Hawaii International Conference on System Sciences, Journal of Business \& Economics Research, etc. Email address: ycho@kdischool.ac.kr.

\section{REFERENCES}

1. Ajzen, I. and Fishbein, M. (1980). Understanding Attitudes and Predicting Social Behavior. Englewood Cliffs, NJ, Prentice-Hall.

2. Alba, Joseph, John Lynch, Barton Weitz, Chris Janiszewski, Richard Lutz, and Stacy Wood (1997), "Interactive Home Shopping: Consumer, Retailer, and Manufacturer Incentives to Participate in Electronic Marketplaces," Journal of Marketing, (July) 61, 38-53.

3. Bearden, William O. and Jesse E. Teel (1983), "Selected Determinants of Consumer Satisfaction and Complaint Reports," Journal of Marketing Research, 20, February, 21-8.

4. Bitner, M. J., Brown, Stephen W., and Meuter, Matthew L. (2000), "Technology Infusion in Service

5. Encounters," Journal of the Academy of Marketing Science, (Winter), 28, 1, 138-149.

6. Cardozo, R. N. (1965). An Experimental Study of Customer Effort, Expectation, and Satisfaction. Journal of Marketing Research, 2, August, 244-49.

7. Cho, Y. (2010), "An Analysis of Customer Expectations/Dissatisfaction toward Perishable Grocery Goods in the Online Environment" under review.

8. (2009), “Assessing Customers' Attitudes/Expectations toward Online Grocery Businesses,"

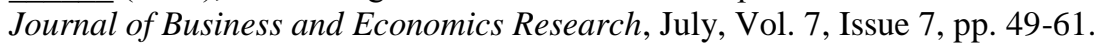

9. (2008), "Effects of Social Networking Sites (SNSs) on Hyper Media Computer Mediated Environments (HCMEs)," International Business \& Economics Research Journal (IBER). Vol 7, Issue 7, pp. $27-40$.

10. $\quad$ and Ha, J. (2004), "Consumer Choice Behavior On the Web: The Effects of Product Attributes on

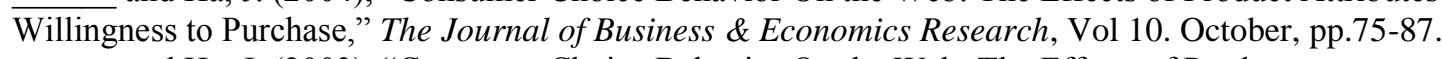

11. __ and Ha, J. (2003), "Consumer Choice Behavior On the Web: The Effects of Product 
12. Attributes on Willingness to Purchase," The Journal of Business \& Economics Research, Vol 10. October, pp.75-87.

13. _ Im, Il, Fjermestad, J. \& Hiltz, S. (2003), “The Impact of Product Category on Customer Dissatisfaction in Cyberspace," A paper has been accepted in a Special Section on Electronic Customer Relationship Management in the Business Process Management Journal, Winter.

14. Daft, Richard L and Lengel, R. H. (1986), "Information Richness Requirements, Media Richness and Structural Design," Management Science, 32, 5, 554-571.

15. Davis, F. D. (1989). Perceived Usefulness, Perceived Ease of Use, and User Acceptance of Information Technology. MIS Quarterly, 13(3), September, 319-340.

16. Degeratu, Alexandru M., Rangaswamy, Arvind, and Wu, Jianan (2001), "Consumer Choice Behavior in Online and Traditional Supermarkets: The Effects of Brand Name, Price, and Other Search Attributes," International Journal of Research in Marketing, Vol. 17, No. 1, pp.55-78.

17. Dick, Alan, Chakravarti, Dipankar, and Biehal, Gabriel (1990), "Memory-Based Inferences During Consumer Choice," Journal of Consumer Behavior, Vol. 17, June, pp.82-93.

18. Dobos, Jean (1992), "Gratification Models of Satisfaction and Choice of Communication Channels and Organizations," Communication Research, 19, February, pp. 29-51.

19. Engel, J. F. and Blackwell, R. D. (1982). Consumer Behavior (4 ${ }^{\text {th }}$ ed.). New York, Holt, Rinehart and Winston.

20. Geuens, M, Brengman, M., and S'Jergers, R. (2003), "Food Retailing, Now and in the Future: A Consumer Perspective," Journal of Retailing and Consumer Services, Vol.10, No.4, pp.241-251.

21. Fazio, R.H. (1995), Attitudes as Object-Evaluation Associations: Determinants, Consequences, and Correlates of Attitude Accessibility, in R.E.Petty and J.A.Krosnick (eds.), Attitude Strength: Antecedents and Consequences, pp.247-282. Mahwah, NJ: Erlbaum.

22. Fazio, R. H. (1990), "Multiple Processes by Which Attributes Guide Behavior: The MODE Model as an Integrated Framework, in M.P.Zanna (ed.), Advances in Experimental Social Psychology, Vol. 23, pp.75109, San Diego, CA: Academic Press.

23. Festinger, L. (1957). A Theory of Cognitive Dissonance. Stanford, California: Stanford University Press.

24. Figueiredo, John M. de (2000), "Finding Sustainable Profitability in Electronic Commerce," Sloan Management Review, Summer.

25. Forsythe, S.M. and Shi, B. (2003), "Consumer Patronage and Risk Perceptions in Internet Shopping," Journal of Business Research, Vol. 56, pp. 867-75.

26. Frambach, R.T., Barkema, H.G., Nooteboom, B., and Wedel, M. (1998), “Adoption of a Service Innovation in the Business Market: A Empirical Test of Supply-side Variables," Journal of Business Research, Vol.41, pp.161-174.

27. Hansen, Torben (2005), "Consumer Adoption of Online Grocery Buying: A Discriminant Analysis," International Journal of Retail \& Distribution Management, Vol. 33, No. 2, pp. 101-121.

28. Hiltz, Starr Roxanne and Turoff, Murray (1978), The Network Nation: Human Communication via Computer, Reading, MA: Addison Wesley.

29. Hoffman, Donna L. and Novak, Thomas P. (1996), "Marketing in Hypermedia Computer-Mediated Environments: Conceptual Foundations," Journal of Marketing, 60, Winter, pp.50-68.

30. __ and __ and Chatterjee, Patrali (1995), "Commercial Scenarios for the Web: Opportunities and Challenges," Journal of Computer-Mediated Communication, JCMC, Special Issue on Electronic Commerce, 1, 3, http://www.ascusc.org/jcmc/vol1/issue3/hoffman.html.

31. Kiely, T. (1996), "The Pleasures and Perils of Selling in Cyberspace", Insights from Marketing Science Institute, Winter/Spring 1997, Reprinted by Permission of Harvard Business Review in Briefings from Editors, September-October 1996.

32. Lam, Shun Yin, Chiang, Jeongwen, and Parasuraman, A. (2008), "The Effects of the Dimensions of Technology Readiness on Technology Acceptance: An Empirical Analysis," Journal of Interactive Marketing, Vol. 22, No. 4, Autumn, pp. 19-39.

33. Oliver, Richard L. (1997), Satisfaction: A Behavioral Perspective on the Consumer, Irwin McGraw-Hill.

34. Palmgreen Philip and Rayburn, J. D. II (1985), “A Comparison of Gratification Models of Media Satisfaction," Communication Monographs, 52, December pp. 334-346. 
35. Rafaeli, Sheizaf (1988), "Interactivity: From New Media to Communication," in Advancing

Communication Science: Merging Mass and Interpersonal Processes, R.P. Hawkins, J.M. Wiemann, and

S. Pingree, eds. Newbury Park, CA: Sage Publications, pp.110-134.

36. Rice, Ronald E. (1993), "Media Appropriateness: Using Social Presence Theory to Compare Traditional and New Organizational Media," Human Communication Research, 19, 4, June 451-484.

37. and Love, Gail (1987), "Electronic Emotion: Socioemotional Content in a Computer-Mediated Communication Network," Communication Research, 14, 1, February, 85-108.

38. Rogers, Everett M. (2003), Diffusion of Innovations, $5^{\text {th }}$ ed., New York: The Free Press.

39. Song, Ji Hee and Zinkhan, George M. (2998), "Determinants of Perceived Web Site Interactivity," Journal of Marketing, Vol. 72, March, pp.99-103.

40. Steuer, Jonathan (1992), "Defining Virtual Reality: Dimensions Determining Telepresence," Journal of Communication, 42, 4, pp.73-93.

41. Wenner, Lawrence A. (1986), "Model Specification and Theoretical Development in Gratifications Sought and Obtained Research: A Comparison of Discrepancy and Transactional Approaches," Communication Monographs, 53, June, pp. 160-179. 
NOTES 